\title{
Long-term, regular remote ischemic preconditioning improves endothelial function in patients with coronary heart disease
}

\author{
Y. Liang, Y.P. Li, F. He, X.Q. Liu and J.Y. Zhang
}

Department of Cardiology, The First Affiliated Hospital of Zhengzhou University, Zhengzhou, China

\begin{abstract}
Remote ischemic preconditioning (RIPre) can prevent myocardial injury. The purpose of this study was to assess the beneficial effects of long-term regular RIPre on human arteries. Forty patients scheduled for coronary artery bypass graft (CABG) surgery were assigned randomly to a RIPre group $(n=20)$ or coronary heart disease $(C H D)$ group $(n=20)$. Twenty patients scheduled for mastectomy were enrolled as a control group. RIPre was achieved by occluding arterial blood flow 5 min with a mercury sphygmomanometer followed by a 5 -min reperfusion period, and this was repeated 4 times. The RIPre procedure was repeated 3 times a day for 20 days. In all patients, arterial fragments discarded during surgery were collected to evaluate endothelial function by flow-mediated dilation (FMD), CD34 ${ }^{+}$monocyte count, and endothelial nitric oxide synthase (eNOS expression). Phosphorylation levels of STAT-3 and Akt were also assayed to explore the underlying mechanisms. Compared with the CHD group, long-term regular RIPre significantly improved FMD after 20 days $(8.5 \pm 2.4$ vs $4.9 \pm 4.2 \%, P<0.05)$ and significantly reduced troponin after CABG surgery $(0.72 \pm 0.31$ and $1.64 \pm 0.19, \mathrm{P}<0.05)$. RIPre activated STAT-3 and increased $\mathrm{CD}_{3}{ }^{+}$endothelial progenitor cell counts found in arteries. Long-term, regular RIPre improved endothelial function in patients with CHD, possibly due to STAT-3 activation, and this may have led to an increase in endothelial progenitor cells.
\end{abstract}

Key words: Remote ischemic preconditioning; endothelial function; coronary heart disease; STAT-3

\section{Introduction}

Studies have shown that remote ischemic preconditioning (RIPre) can reduce infarct size and decrease ischemia-reperfusion injury, making it an attractive, novel strategy to prevent myocardial injury $(1,2)$. It has been shown to be effective in reducing myocardial reperfusion injuries in both experimental and clinical settings (3). Recently, the application of RIPre for patients with acute myocardial infarction during ambulance transit was shown to reduce infarct size, but the mechanism is largely unknown (4). Signal transducer and activator of transcription-3 (STAT-3) activation is thought to play a cardioprotective role during myocardial infarction by ischemic preconditioning.

Patients with coronary heart disease (CHD) who experience myocardial infarction exhibit endothelial dysfunction (5). This contributes to the pathogeneses of atherosclerosis and its complications and is closely related to cardiovascular events. RIPre before hospital admission increases myocardial salvage and has a favorable safety profile (6); however, the direct role of RIPre in regulating human arterial function remains elusive.
The aims of the present study were twofold: to identify the beneficial effects of long-term regular RIPre in human arteries, especially with regard to endothelial function protection, and to determine its potential mechanisms.

\section{Material and Methods}

\section{Study design}

Forty patients who had significant coronary arterial stenosis and were scheduled for coronary artery bypass graft $(C A B G)$ surgery were enrolled in the study. The patients were randomly assigned to the RIPre $(n=20)$ or CHD group $(n=20)$. Twenty patients with breast cancer who were scheduled for mastectomy were included as a control group. Exclusion criteria were the presence of an acute coronary syndrome, heart failure, hypertrophic cardiomyopathy, uncontrolled hypertension, serum creatinine concentration $>2 \mathrm{mg} / \mathrm{dL}$, or anticipation of noncompliance with the study protocol. The study objectives and protocol were fully explained, and written informed consent was obtained from all patients. This study was

Correspondence: Jinying Zhang: <x201017liangying@126.com>. 
approved by the regional Ethics Committee in accordance with the standards of the Declaration of Helsinki.

RIPre was administered while upper arm blood pressure was monitored 3 times a day for 20 days. A blood pressure cuff was placed around the upper arm and inflated to $200 \mathrm{mmHg}$ to occlude arterial blood flow for $5 \mathrm{~min}$. The cuff was then deflated to allow reperfusion. The procedure was repeated 4 times at 5-min intervals. Limb ischemia was confirmed by a change in the color of the skin and a decrease in skin temperature. Following limb reperfusion, the skin color returned to pink, and the skin temperature returned to the baseline level. In the CHD group, blood pressure was routinely measured three times daily. After 20 days, all patients underwent CABG surgery, and discarded artery fragments were collected following the procedure for later analysis $(7,8)$. Routine patient treatment for CHD was maintained during the study in both the RIPre and CHD groups. Antihypertensive treatment was titrated to achieve a target blood pressure of $<130 / 80$ or $<140 / 90 \mathrm{mmHg}$ for patients with or without diabetes, respectively, during the study period.

\section{Measurement of flow-mediated vasodilation (FMD) response}

FMD response was measured at baseline and on day 20 and used as an index of endothelial function. Color Doppler ultrasound measurement of the brachial artery was performed in the resting state end-diastolic dimension, (D0), pneumatic compression to $250-300 \mathrm{mmHg}$ was maintained for $5 \mathrm{~min}$, and $60-90 \mathrm{~s}$ after deflation, reactive hyperemia of the brachial artery diastolic diameter (D1) was determined. The color Doppler evaluation of FMD is reported as the percent change in brachial artery diameter and was calculated as follows: (D1-D0)/ D0) $\times 100$. FMD values $\geqslant 10 \%$ and $<10 \%$ were considered to indicate normal vascular endothelial function and endothelial dysfunction, respectively.

\section{CD34 ${ }^{+}$monocyte count by flow cytometry}

$\mathrm{CD}_{3}{ }^{+}$monocyte and leukocyte counts were performed in all patients at baseline and on day 20. A total of $10 \mu \mathrm{L}$ blood was added to two tubes, and IgG antibody was added to one tube as a control. Fluorescein isothiocyanate (FITC)-conjugated CD34 and phycoerythrin (PE)-conjugated CD38 antibodies were added to the remaining patient samples and incubated for $30 \mathrm{~min}$ in the dark. Subsequently, $1 \mathrm{~mL}$ erythrocyte lysis buffer was added, and after an additional $15 \mathrm{~min}$ in the dark, phosphate-buffered saline was added to adjust the cell concentration for flow cytometry (FACSCAN Becton Dickinson, USA). The antibody positive rate was recorded as the percentage of CD34+ leukocytes.

\section{Arterial CD34 ${ }^{+}$monocytes by immunohistochemisty}

Tissue sections were stained as previously described (9). Cryosections of internal mammary artery fragments
$(7,8)$ were stained for CD34 (BD Pharmingen, USA), counterstained with FITC-fluorescence (Sigma, USA) and mounted with fluorescent mounting medium (Dako, Denmark). Sections were examined using a Nikon E600 fluorescence microscope (Japan) and the Lucia Measurement software 4.6 (India).

\section{Endothelial nitric oxide synthase (eNOS) mRNA expression by semiquantitative RT-PCR}

Total RNA was extracted from arterial tissue samples using the SV total RNA Isolation System (Promega, USA) and diluted in $30 \mu \mathrm{L}$ RNA-free water. The purity of RNA can be confirmed by RNA electrophoresis. The RevertAid First Strand cDNA Synthesis Kit (Thermo Scientific, USA) was used to obtain $3 \mu \mathrm{g}$ total RNA. The reaction mixture contained $2 \mu \mathrm{L}$ cDNA, $10 \mu \mathrm{L} 2 \times$ PCR Taqmix, $1 \mu \mathrm{L}$ upstream and downstream primers, and $5 \mu \mathrm{L}$ RNA enzyme water, for a total volume of $20 \mu \mathrm{L}$. The primers used were as follows: eNOS-specific (299 bp) sense, 5'TTCCGGGGATTCTGGCAGGAG-3' and antisense, 5'GCCAT-GGTAACATCGCCGCAG-3'); glyceraldehyde phosphate dehydrogenase (GAPDH)-specific (343 bp) sense, 5'-CTCTAAGGCTGTGGGCAAGGTCAT-3' and antisense, 5'-GAGATCCACCACCCTGTTGCTGTA-3'. The 35 PCR cycles were carried out as follows: $94^{\circ} \mathrm{C}$ for $5 \mathrm{~min}, 94^{\circ} \mathrm{C}$ for $30 \mathrm{~s}, 65^{\circ} \mathrm{C}$ for $45 \mathrm{~s}$, and $72^{\circ} \mathrm{C}$ for $30 \mathrm{~s}$. RT-PCR products were analyzed by $2 \%$ agarose gel electrophoresis, visualized with ethidium bromide, and quantified by densitometry. The results are reported as the ratio of eNOS and GAPDH.

\section{Western blotting}

Fragments of arterial tissue obtained during CABG surgery were used to measure protein phosphorylation by immunoblotting for survival kinases (10). The excised tissue was clamped between stainless steel tongs precooled with liquid nitrogen, frozen in liquid nitrogen, and stored at $-80^{\circ} \mathrm{C}$. Approximately $100 \mathrm{mg}$ powdered arterial tissue was used for protein extraction. Frozen tissue samples were homogenized on ice in $0.5-\mathrm{mL}$ icecold lysis buffer containing $30 \mathrm{mM}$ HEPES, $20 \mathrm{mM} \mathrm{KCl}$, $2.5 \mathrm{mM}$ EGTA, $2.5 \mathrm{mM}$ EDTA, $40 \mathrm{mM}$ sodium fluoride, $4 \mathrm{mM}$ sodium pyrophosphate, $1 \mathrm{mM}$ sodium orthovanadate, $10 \%$ glycerol, $1 \%$ Nonidet P-40, a phosphatase inhibitor cocktail (Sigma), and a protease inhibitor cocktail (Complete Mini; Roche Applied Science, Germany). Following electrophoresis and blotting, membranes were incubated overnight at $4^{\circ} \mathrm{C}$ with antibodies against ${ }^{705} \mathrm{Tyr}$ phospho-STAT-3, total STAT-3, total serine/threonineprotein kinase (Akt), and ${ }^{473}$ Ser-phospho-Akt (Cell Signaling Technology, USA). Beta-actin (Sigma) was used as a loading control. After washing in Tris-buffered saline and Tween-20, the membranes were incubated for $1 \mathrm{~h}$ at room temperature with horseradish peroxidaseconjugated anti-human IgG secondary antibody (1:2000, Santa Cruz Biotechnologies, USA), and the bound 
antibody was detected using an enhanced chemiluminescence Western blotting kit (Santa Cruz Biotechnologies). The densities of bands with appropriate molecular masses (60 kDa for Akt and $80 \mathrm{kDa}$ for STAT-3) were semiquantitatively determined using a LAS-3000 mini Lumino image analyzer (Fujifilm, Japan). Blood troponin concentration was assayed in all patients after CABG surgery using a diabody one-step sandwich enzyme immunoassay (Access Immunoassay System; Beckman Coulter, USA).

\section{Statistical analysis}

Data are reported as means $\pm S D$ for continuous variables or frequency percentages for categorical variables. The Kolmogorov-Smirnov test was used to determine the normality of distribution for continuous variables. Multiple comparisons were evaluated by oneway ANOVA, and the differences between two groups were analyzed by Student-Newman-Keuls post hoc test. Either chi-square or Fisher's exact tests were used to compare differences between categorical variables. Differences of continuous variables that were not normally distributed were compared with Kruskal-Wallis or MannWhitney U-tests. Differences were considered to be statistically significant if the $P$ value was less than 0.05 . All analyses were performed with the S-Plus statistical package (Mathsoft Inc., USA).

\section{Results}

\section{Patient characteristics}

As shown in Table 1, the control, RIPre, and CHD groups did not differ significantly in age, gender, body mass index, blood pressure, or smoking status. At the beginning of the study, the patients in RIPre and CHD groups were well matched with respect to age, gender, angina class, and cardiovascular risk factors. On echocardiography, left ventricle (LV) end-diastolic dimensions were similar in the two groups. In addition, there were no differences between the RIPre and CHD groups in medical treatment (Table 1). The use of beta blockers, calcium channel blockers, and statins was similar between the two groups. Coronary angiography showed serious lesions in coronary vessels in all RIPre and CHD patients, and all underwent CABG surgery (Table 2). Hematologic analysis showed that the three groups had similar white cell and mononuclear cell counts (Table 3 ).

FMD and eNOS mRNA expression showed that longterm regular RIPre improved arterial endothelial function

RIPre can improve arterial endothelial function in patients with CHD. At baseline, patients in both the CHD and RIPre groups had lower FMD than controls $(F M D=12.8 \pm 3.5 \%, 4.6 \pm 3.2 \%$, and $5.5 \pm 3.3 \%$ in the control, RIPre and CHD groups, respectively; both $\mathrm{P}<0.05$ vs control; Table 2). FMD was significantly improved in the RIPre group compared to the CHD group 30 days after treatment $(8.5 \pm 2.4 \%$ vs $4.9 \pm 4.2 \%$, $\mathrm{P}<0.05)$. eNOS mRNA levels were measured by semiquantitative RT-PCR. Total cell RNA was isolated, amplified, and then subjected to RT-PCR with eNOSand GAPDH-specific primers in separate reactions. As shown in Figure 1, RIPre treatment significantly enhanced eNOS mRNA expression compared with the CHD group $(n=20, P<0.05)$.

Interestingly, troponin expression was significantly lower in the RIPre group than the CHD group after CABG surgery $(0.72 \pm 0.31 \mathrm{ng} / \mathrm{L}$ and $1.64 \pm 0.19 \mathrm{ng} / \mathrm{L}$, $\mathrm{P}<0.05$ ), indicating that less cardiomyocyte necrosis occurred during the procedure.

\section{Long-term regular RIPre activated STAT-3}

There were no significant differences in total Akt or STAT-3 protein levels among the study groups. As illustrated in Figures 2 and 3, phospho-Akt levels were significantly enhanced in RIPre compared with control group patients $(\mathrm{P}<0.05)$. While RIPre treatment was more effective in increasing endothelial function than medical treatment alone in the CHD group, Akt was significantly more phosphorylated in RIPre than in CHD, suggesting that another signaling pathway might play a role in the enhanced cardioprotection afforded by this treatment. When testing the Survivor Activating Factor Enhancement (SAFE) pathway (11), phospho-STAT-3 levels were significantly increased following RIPre. Interestingly, RIPre significantly increased phosphoSTAT-3 levels compared with the controls and CHD patients. ( $P<0.05$, Figure 3 ).

\section{Long-term regular RIPre increased immunohistochemical staining of endothelial progenitor cells $\left(\mathrm{CD}_{34}{ }^{+}\right)$in arteries}

The arterial $\mathrm{CD} 34^{+}$cells of patients in the RIPre group exhibited increased immunofluorescence compared with those of patients in the CHD group. The arterial CD34 ${ }^{+}$ cells of patients in the control and CHD groups had the highest and lowest immunofluorescence, respectively, and the immunofluorescence observed in the RIPre group was significantly higher than that in the $\mathrm{CHD}$ group $(n=20, P<0.05$; Figure 4$)$. The number of $C D 34^{+}$cells was significantly higher in the control group than in patients in the CHD or RIPre group. At the beginning of the study, the absolute number of $\mathrm{CD} 34^{+}$cells was significantly different $(2.35 \pm 0.72$ cells $/ \mu \mathrm{L}, 1.48 \pm 0.49$ cells $/ \mu \mathrm{L}$ and $1.56 \pm 0.37$ cells $/ \mu \mathrm{L}, \mathrm{P}<0.05)$ in control group patients than in patients in the CHD and RIPre groups. On the other hand, no significant difference was noted in the number of CD34 ${ }^{+}$cells in the RIPre and CHD groups. On day 20, the numbers of $\mathrm{CD} 34^{+}$cells in the RIPre and CHD groups were significantly different 
Table 1. Clinical, electrocardiographic and echocardiographic data of remote ischemic preconditioning (RIPre) and coronary heart disease (CHD) patients.

\begin{tabular}{lccc}
\hline Clinical data & Control & RIPre & CHD \\
\hline Age (years) & $64 \pm 10$ & $64 \pm 10$ & $64 \pm 10$ \\
Gender (male/female) & $11 / 9$ & $12 / 8$ & $8 / 12$ \\
CCS class & 0 & $2.4 \pm 0.7$ & $2.2 \pm 0.6$ \\
NYHA functional class & & & \\
II & 0 & 10 & 10 \\
III or IV & 0 & 10 & 10 \\
Hypertension & 2 & $3 / 17$ & $4 / 16$ \\
Diabetes & 0 & $5 / 15$ & $6 / 14$ \\
Hypercholesterolemia & 1 & 13 & 12 \\
BMI & $3.85 \pm 7.3$ & $24.78 \pm 6.8$ & $23.95 \pm 7.5$ \\
Current Smoking & $7 / 13$ & $8 / 12$ & $6 / 10$ \\
Previous myocardial infarction & 0 & 13 & 12 \\
EF\% & $60 \pm 12$ & $60 \pm 7$ & $58 \pm 10$ \\
\hline
\end{tabular}

Data are reported as means \pm SD or number. CCS: Canadian Cardiovascular Society; NYHA: New York Heart Association; BMI: body mass index; EF\%: ejection fraction.

$(1.79 \pm 0.31$ cells $/ \mu \mathrm{L}$ vs $1.34 \pm 0.20$ cells $/ \mu \mathrm{L}, \mathrm{P}<0.05$ Figure 5). Because the increase in endothelial progenitor cells (EPCs) and improvement in endothelial function may be correlated, we carried out a regression analysis that revealed a slight but significantly positive correlation between FMD and the number of $\mathrm{CD}_{3} 4^{+}$cells $(r=0.46$, $\mathrm{P}<0.05)$.

\section{Discussion}

The present study showed that RIPre is effective in improving endothelial function in patients with $\mathrm{CHD}$ and that the mechanism may involve activation of the Akt and STAT-3 pathways. The findings also indicated that improvement in endothelial function was related to increased EPCs in CHD.

Ischemic preconditioning experiments in animal models have demonstrated significant cardioprotective effects and reductions in the size of myocardial infarcts. A recent clinical study found that administering RIPre to patients with acute myocardial infarction while still in transit in a ambulance reduced infarct size (11).

Here we demonstrated that long-term, regular RIPre had a cardioprotective effect. After CABG surgery, the

Table 2. Quantitative coronary angiographic data and medical treatment of remote ischemic preconditioning (RIPre) and coronary heart disease (CHD) patients.

\begin{tabular}{lcc}
\hline Characteristics & RIPre $(\mathrm{n}=20)$ & $\mathrm{CHD}(\mathrm{n}=20)$ \\
\hline Extension of disease & & \\
$\quad$ Single vessel disease (left main lesion) & $8(40 \%)$ & $7(35 \%)$ \\
$\quad$ Multivessel disease & $12(60 \%)$ & $13(65 \%)$ \\
Vessel disease & & \\
LAD involved & $14(70 \%)$ & $13(65 \%)$ \\
Cx involved & $11(55 \%)$ & $10(50 \%)$ \\
RCA involved & $13(65 \%)$ & $14(70 \%)$ \\
Medication & & \\
ACE inhibitors & $16(80 \%)$ & $15(75 \%)$ \\
Beta-blockers & $19(95 \%)$ & $20(100 \%)$ \\
Diuretics & $4(20 \%)$ & $6(30 \%)$ \\
Calcium antagonists & $3(15 \%)$ & $5(25 \%)$ \\
Statins & $20(100 \%)$ & $20(100 \%)$ \\
\hline
\end{tabular}

Data are reported as number and percent. LAD: left anterior descending artery; Cx: left circumflex artery; RCA: right coronary artery; ACE: angiotensin-converting enzyme. There were no significant differences between groups (chi-square test). 
Table 3. Number of endothelial progenitor cells $\left(\mathrm{CD} 34^{+}\right)$, white cells and flow-mediated dilation (FMD) in remote ischemic preconditioning (RIPre) and coronary heart disease (CHD) patients and the control group.

\begin{tabular}{lcccccc}
\hline \multirow{2}{*}{ Features } & Control & \multicolumn{2}{c}{ RIPre } & & \multicolumn{2}{c}{ CHD } \\
\cline { 3 - 4 } \cline { 6 - 7 } & & Before & After & & Before & After \\
\hline${\text { White cells }\left(10^{3} / \mathrm{mL}\right)}$ & $9.86 \pm 2.79$ & $8.96 \pm 2.87$ & $7.93 \pm 3.04$ & & $6.92 \pm 1.67$ & $7.34 \pm 2.56$ \\
CD34 $^{+}(\mathrm{cells} / \mu \mathrm{L})$ & $2.35 \pm 0.72$ & $1.48 \pm 0.49$ & $1.79 \pm 0.31^{* \#}$ & & $1.56 \pm 0.37$ & $1.34 \pm 0.20^{*}$ \\
FMD $(\%)$ & $12.8 \pm 3.5$ & $4.6 \pm 3.2$ & $8.5 \pm 2.4^{* \#}$ & & $5.5 \pm 3.3$ & $4.9 \pm 4.2^{*}$ \\
\hline
\end{tabular}

Data are reported as means $\pm \mathrm{SD}$. ${ }^{*} \mathrm{P}<0.05$ vs control; ${ }^{*} \mathrm{P}<0.05$ vs before treatment (Student-NewmanKeuls test).

mean troponin levels in the RIPre $(0.72 \pm 0.31 \mathrm{ng} / \mathrm{L})$ and CHD groups $(1.64 \pm 0.19 \mathrm{ng} / \mathrm{L})$ were significantly different, indicating that RIPre protected patients and reduced myocardial cell damage. This finding is consistent with previous reports $(12,13)$. As most patients with CHD have endothelial dysfunction, we propose that the cardioprotective effect of long-term regular RIPre is related to improved endothelial function.
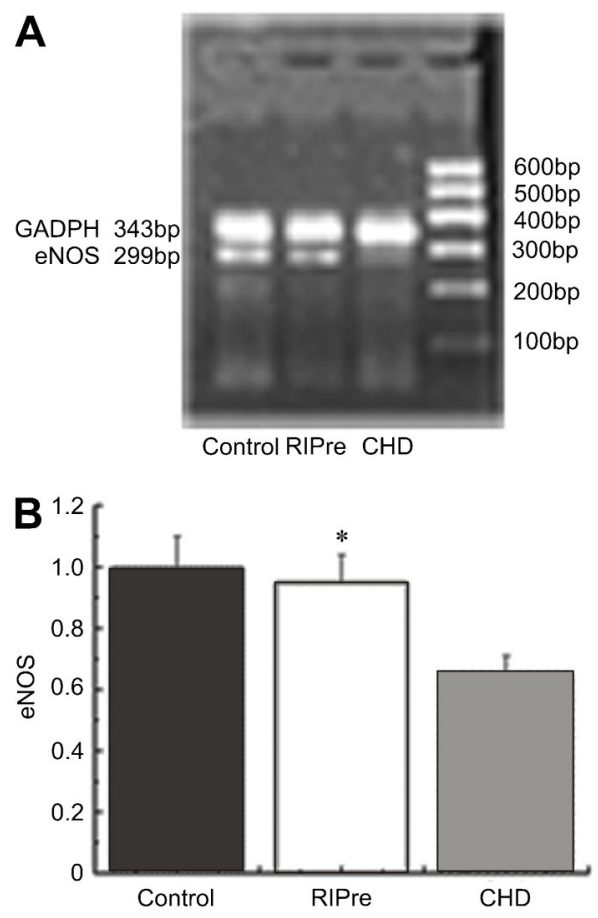

Figure 1. $A$, Effects of remote ischemic preconditioning (RIPre) on endothelial expression of endothelial nitric oxide synthase (eNOS) mRNA as measured by semiquantitative RT-PCR. RIPre caused an increase in eNOS mRNA expression. $B$, Relative expression of eNOS mRNA (density ratio, eNOS:GADPH) is reported as means $\pm S E$ for $n=20$ in each group. ${ }^{*} \mathrm{P}<0.05$ vs CHD (Student-Newman-Keuls test). Note that the example does not exactly reflect the mean value of all samples.
This study provides some insight into the relationship between regular RIPre and improved endothelial function in CHD patients. Currently, echocardiography or arterial FMD is used as a standard tool for the evaluation of endothelium-dependent vasodilatation. In this study, assessment of FMD, endothelial progenitor cells, CD34 + monocyte counts, and eNOS mRNA gene expression were carried out to evaluate endothelial function (11), and we
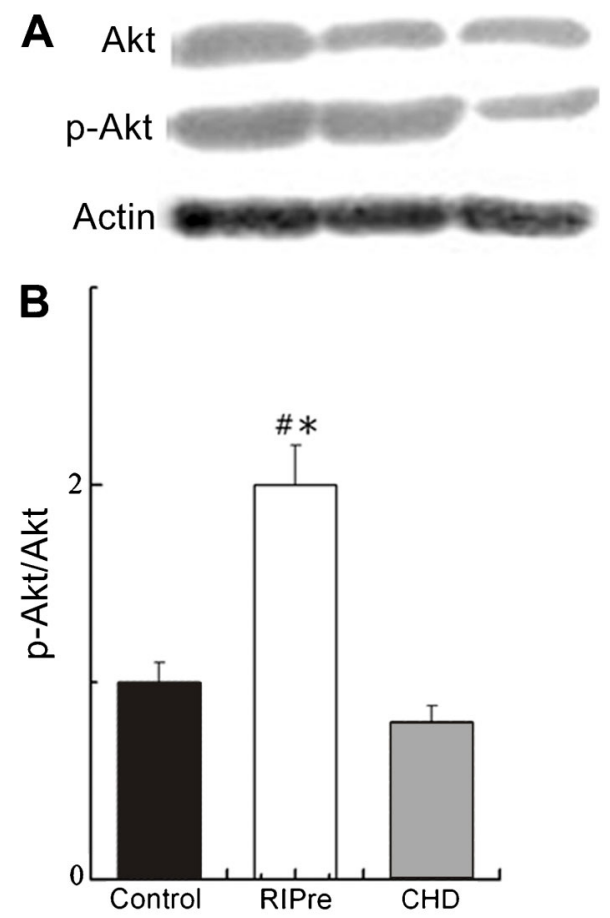

Figure 2. $A$, Representative Western blot showing phosphorylated serine-threonine protein kinase (p-Akt), total Akt, and actin in arterial tissues. B, Ratio of p-Akt to Akt. Data are reported as means $\pm S E$ for $n=20$ in each group. RIPre: remote ischemic preconditioning; $\mathrm{CHD}$ : coronary heart disease. ${ }^{*} \mathrm{P}<0.05$ vs control group; ${ }^{\#} \mathrm{P}<0.05$ vs CHD (Student-Newman-Keuls test). Note that the immunoblot example does not exactly reflect the mean value of all samples. 

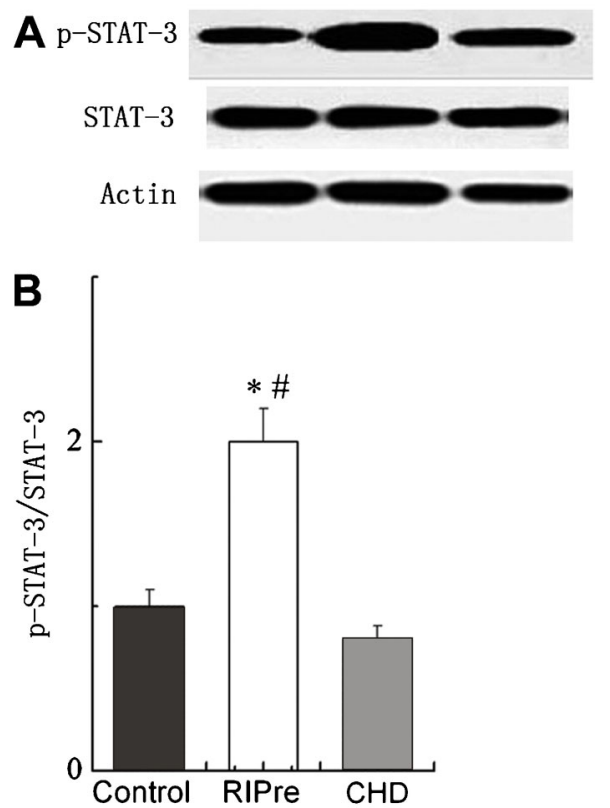

Figure 3. $A$, Representative Western blot of phosphorylated STAT-3 (p-STAT-3), total STAT-3, and actin in arterial tissue. $B$, Ratio of p-STAT-3 to STAT-3. Data are reported as means \pm SE for $n=20$ in each group. RIPre: remote ischemic preconditioning; $\mathrm{CHD}$ : coronary heart disease. ${ }^{*} \mathrm{P}<0.05$ vs control group; ${ }^{\#} \mathrm{P}<0.05$ vs CHD (Student-Newman-Keuls test). Note that the immunoblots do not exactly reflect the mean values of all samples.

found significant improvements consistent with previously reported results (14). In the RIPre group, FMD improved from $4.6 \pm 3.2 \%$ to $8.5 \pm 2.4 \%$, but this change was not significant in the CHD group $(5.5 \pm 3.3 \%$ vs $4.9 \pm 4.2 \%)$ After treatment, FMD in the RIPre patients was close to normal and significantly improved compared with the CHD group. The observed increase in FMD demonstrates that long-term regular RIPre significantly improved endothelial function. However, these methods test peripheral arteries rather than coronary vascular endothelial function. To this end, we tested samples of the internal thoracic artery obtained during surgery $(7,8)$. eNOS mRNA gene expression in artery samples $(7,8)$ was higher in the RIPre group than in the CHD group. These results indicate that increased eNOS mRNA gene expression resulted from improved endothelial function (15).

Recently, ischemic preconditioning studies demonstrated activation of STAT-3 as a part of the SAFE pathway $(16,17)$. Studies in animal models have confirmed that the cardioprotective effects of RIPre are due to STAT-3 activation $(18,19)$. The SAFE pathway is thought to have a cardioprotective effect related to RIPre in myocardial infarction $(9,20)$, and its role has been confirmed in patients after CABG surgery in whom troponin values were significantly different between patients in RIPre and CHD groups. This indicates that in the event of myocardial infarction, long-term regular RIPre can protect myocardial cells and reduce myocardial necrosis. In this model, RIPre activates STAT-3 (SAFE pathway), increases $\mathrm{p}-\mathrm{Akt}$, and then increases eNOS mRNA gene expression, resulting in improved endothelial function and FMD. Hence, we presume that the increase in eNOS mRNA gene expression is correlated with the activation of STAT-3 (SAFE pathway). However, as this was a human experiment, blockers could not be applied to test our hypothesis.
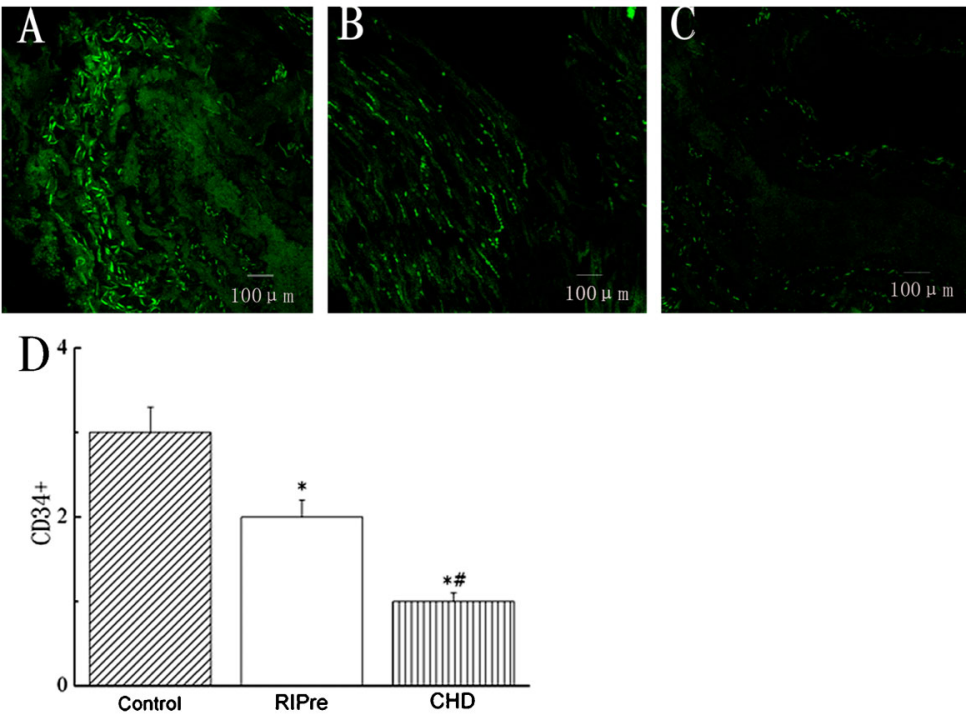

Figure 4. Representative micrographs of immunofluorescence staining of arterial $\mathrm{CD} 34^{+}$cells in the $A$, control group; $B$, remote ischemic preconditioning (RIPre) group; and $C$, coronary heart disease (CHD) group. Cells expressing hematopoietic progenitor cell antigen $\mathrm{CD} 34\left(\mathrm{CD} 34^{+}\right)$ were significantly reduced in the CHD group compared with the control group but were significantly increased by RIPre $(\mathrm{P}<0.05)$. $D$, Relative fluorescence of EPC staining of endothelial progenitor cells (EPCs); CD34 ${ }^{+}$ staining. Data are reported as means $\pm S E$ for $\mathrm{n}=20$ in each group. ${ }^{*} \mathrm{P}<0.05$ vs control group; ${ }^{\#} \mathrm{P}<0.05$ vs RIPre group (Student-NewmanKeuls test). Note that the example does not exactly reflect the mean value of all samples. 
A

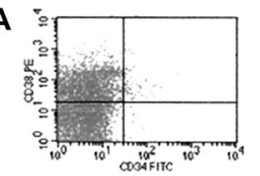

Conclusion: $\mathrm{CD} 34+=0.90 \%$ Control before

B

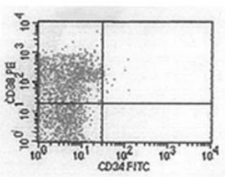

Conclusion: $\mathrm{CD} 34+=0.47 \%$ RIPre before

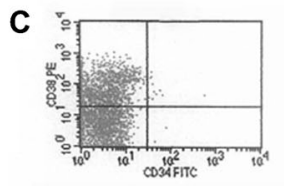

Conclusion: $\mathrm{CD} 34+=0.43 \%$ $\mathrm{CHD}$ before
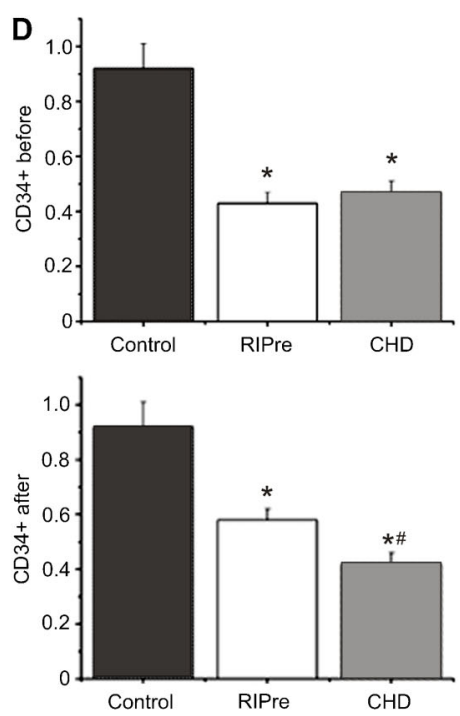

Figure 5. $A$, Representative flow cytometry measurements of CD34 ${ }^{+}$monocytes in blood before and after treatment in the $A$, control group; $B$, remote ischemic preconditioning (RIPre) group; and $C$, coronary heart disease (CHD) group. $D, C D 34^{+}$ monocytes in blood before and after treatment. Data are reported as means $\pm \mathrm{SE}$. ${ }^{*} \mathrm{P}<0.05$ vs control group; ${ }^{*} \mathrm{P}<0.05$ vs RIPre group (Student-Newman-Keuls test).

Stem cell research in the past decade has shown that EPCs, a population of bone marrow-derived cells, circulate in the blood and modulate new vessel formation and homeostasis in adults (21-23). In addition, low EPC number is correlated with poor vascular function (24) and is an independent risk factor for adverse events in CHD patients $(25,26)$. It follows that the number of circulating EPCs may determine the capacity to repair vascular damage and may be viewed as an index of vascular health. The popular concept is that circulating EPCs are protective, and their alteration may account for the progression of endothelial dysfunction and atherosclerosis that are commonly seen in LV dysfunction and CHD (27). The role of EPCs in endothelial dysfunction, however, remains a matter of debate. Due to the difficulties in their identification, limited information is available about the normal range of EPCs in CHD. In addition, earlier studies have been hampered by their retrospective nature and by the lack of uniform criteria to precisely identify EPCs. Studies have mainly focused on cells positive for the CD34 endothelial marker, which is an adhesion molecule expressed in hematopoietic stem cells (28), because it is not expressed in mature endothelium (29). Conversely, there are few data on the pathophysiological significance of other subsets of stem/progenitor cells. The levels of EPCs are decreased in coronary artery disease, and animal models have shown that a decrease in the endogenous pool of progenitor cells may accelerate the course of atherosclerosis $(30,31)$. Similarly, early investigations showed that circulating EPCs are involved in modulating LV remodeling processes that lead to heart failure (32). It was recently reported that patients with ischemic and nonischemic cardiomyopathy have a lower number of EPCs than healthy individuals (33). In the present study, immunohistochemistry of internal mammary artery specimens $(7,8)$ revealed that EPCs were positive for the CD34 endothelial marker and that they increased in CHD. Although this does not prove a causal relationship, we found a significant positive correlation between FMD and CD34 ${ }^{+}$.

Accordingly, overall increases in stem cell number and function have been proposed as a therapeutic means for improving LV function in CHD patients. Stem and progenitor cell circulation and pretreatment of cardiac homing have been shown to reduce infarct size and improve cardiac function.

In conclusion, long-term regular RIPre improved endothelial function in patients with CHD, possibly via STAT-3 activation (SAFE pathway), and may have been associated with an increase in arterial EPCs.

\section{Acknowledgments}

This research was supported by the First Affiliated Hospital of Zhengzhou University. 


\section{References}

1. Hausenloy DJ, Yellon DM. Remote ischaemic preconditioning: underlying mechanisms and clinical application. Cardiovasc Res 2008; 79: 377-386, doi: 10.1093/cvr/cvn114.

2. Heusch G, Schulz R. Remote preconditioning. J Mol Cell Cardiol 2002; 34: 1279-1281, doi: 10.1006/jmcc.2002.2093.

3. Kharbanda RK. Cardiac conditioning: a review of evolving strategies to reduce ischaemia-reperfusion injury. Heart 2010; 96: 1179-1186, doi: 10.1136/hrt.2009.179101.

4. Saxena P, Newman MA, Shehatha JS, Redington AN, Konstantinov IE. Remote ischemic conditioning: evolution of the concept, mechanisms, and clinical application. J Card Surg 2010; 25: 127-134, doi: 10.1111/j.1540-8191.2009. 00820.x.

5. Davel AP, Wenceslau CF, Akamine EH, Xavier FE, Couto GK, Oliveira HT, et al. Endothelial dysfunction in cardiovascular and endocrine-metabolic diseases: an update. Braz J Med Biol Res 2011; 44: 920-932, doi: 10.1590/ S0100-879X2011007500104.

6. Botker HE, Kharbanda R, Schmidt MR, Bottcher M, Kaltoft AK, Terkelsen CJ, et al. Remote ischaemic conditioning before hospital admission, as a complement to angioplasty, and effect on myocardial salvage in patients with acute myocardial infarction: a randomised trial. Lancet 2010; 375: 727-734, doi: 10.1016/S0140-6736(09)62001-8.

7. Bai $X Y$, Liu $X C$, Yang $Q$, Tang $X D$, He GW. The interaction between human urotensin II and vasodilator agents in human internal mammary artery with possible clinical implications. Ann Thorac Surg 2011; 92: 610-616, doi: 10.1016/j.athoracsur.2011.03.094.

8. Rodriguez-Esparragon F, Serna-Gomez JA, HernandezVelazquez E, Buset-Rios N, Hernandez-Trujillo Y, GarciaBello MA, et al. Homocysteinylated protein levels in internal mammary artery (IMA) fragments and its genotype-dependence. S-homocysteine-induced methylation modifications in IMA and aortic fragments. Mol Cell Biochem 2012; 369: 235-246, doi: 10.1007/s11010-012-1387-7.

9. Lacerda L, Somers S, Opie LH, Lecour S. Ischaemic postconditioning protects against reperfusion injury via the SAFE pathway. Cardiovasc Res 2009; 84: 201-208, doi: 10.1093/cvr/cvp274.

10. Xin P, Zhu W, Li J, Ma S, Wang L, Liu M, et al. Combined local ischemic postconditioning and remote preconditioning recapitulate cardioprotective effects of local ischemic preconditioning. Am J Physiol Heart Circ Physiol 2010; 298: H1819-H1831, doi: 10.1152/ajpheart.01102.2009.

11. Tamareille S, Mateus V, Ghaboura N, Jeanneteau J, Croue A, Henrion D, et al. RISK and SAFE signaling pathway interactions in remote limb ischemic perconditioning in combination with local ischemic postconditioning. Basic Res Cardiol 2011; 106: 1329-1339, doi: 10.1007/s00395-011-0210-z.

12. Kerendi $F$, Kin $H$, Halkos ME, Jiang $R$, Zatta $A J$, Zhao ZQ, et al. Remote postconditioning. Brief renal ischemia and reperfusion applied before coronary artery reperfusion reduces myocardial infarct size via endogenous activation of adenosine receptors. Basic Res Cardiol 2005; 100: 404412, doi: 10.1007/s00395-005-0539-2.

13. Loukogeorgakis SP, Williams R, Panagiotidou AT, Kolvekar SK, Donald A, Cole TJ, et al. Transient limb ischemia induces remote preconditioning and remote postconditioning in humans by a K(ATP)-channel dependent mechanism. Circulation 2007; 116: 1386-1395, doi: 10.1161/CIRCULA TIONAHA.106.653782.

14. Jones H, Hopkins N, Bailey TG, Green DJ, Cable NT, Thijssen $\mathrm{DH}$. Seven-day remote ischemic preconditioning improves local and systemic endothelial function and microcirculation in healthy humans. Am J Hypertens 2014; 27: 918-925, doi: 10.1093/ajh/hpu004.

15. Valgimigli $M$, Rigolin GM, Fucili A, Porta MD, Soukhomovskaia $O$, Malagutti $P$, et al. CD34+ and endothelial progenitor cells in patients with various degrees of congestive heart failure. Circulation 2004; 110: 12091212, doi: 10.1161/01.CIR.0000136813.89036.21.

16. Boengler K, Hilfiker-Kleiner D, Drexler H, Heusch G, Schulz R. The myocardial JAK/STAT pathway: from protection to failure. Pharmacol Ther 2008; 120: 172-185, doi: 10.1016/ j.pharmthera.2008.08.002.

17. Boengler K, Hilfiker-Kleiner D, Heusch G, Schulz R. Inhibition of permeability transition pore opening by mitochondrial STAT3 and its role in myocardial ischemia/ reperfusion. Basic Res Cardiol 2010; 105: 771-785, doi: 10.1007/s00395-010-0124-1.

18. Hausenloy DJ, Lecour S, Yellon DM. Reperfusion injury salvage kinase and survivor activating factor enhancement prosurvival signaling pathways in ischemic postconditioning: two sides of the same coin. Antioxid Redox Signal 2011; 14: 893-907, doi: 10.1089/ars.2010.3360.

19. Kelly RF, Lamont KT, Somers S, Hacking D, Lacerda L, Thomas $P$, et al. Ethanolamine is a novel STAT-3 dependent cardioprotective agent. Basic Res Cardiol 2010; 105: 763-770, doi: 10.1007/s00395-010-0125-0.

20. Lecour S. Activation of the protective Survivor Activating Factor Enhancement (SAFE) pathway against reperfusion injury: Does it go beyond the RISK pathway? J Mol Cell Cardiol 2009; 47: 32-40, doi: 10.1016/j.yjmcc.2009.03.019.

21. Takahashi T, Kalka C, Masuda H, Chen D, Silver M, Kearney $M$, et al. Ischemia- and cytokine-induced mobilization of bone marrow-derived endothelial progenitor cells for neovascularization. Nat Med 1999; 5: 434-438, doi: 10.1038/8462.

22. Kocher AA, Schuster MD, Szabolcs MJ, Takuma S, Burkhoff $\mathrm{D}$, Wang $\mathrm{J}$, et al. Neovascularization of ischemic myocardium by human bone-marrow-derived angioblasts prevents cardiomyocyte apoptosis, reduces remodeling and improves cardiac function. Nat Med 2001; 7: 430-436, doi: 10.1038/86498.

23. Rauscher FM, Goldschmidt-Clermont PJ, Davis BH, Wang $T$, Gregg D, Ramaswami $P$, et al. Aging, progenitor cell exhaustion, and atherosclerosis. Circulation 2003; 108: 457463, doi: 10.1161/01.CIR.0000082924.75945.48.

24. Hill JM, Zalos G, Halcox JP, Schenke WH, Waclawiw MA, Quyyumi AA, et al. Circulating endothelial progenitor cells, vascular function, and cardiovascular risk. $N$ Engl $\mathrm{J}$ Med 2003; 348: 593-600, doi: 10.1056/NEJMoa022287.

25. Werner N, Kosiol S, Schiegl T, Ahlers P, Walenta K, Link A, et al. Circulating endothelial progenitor cells and cardiovascular outcomes. N Engl J Med 2005; 353: 999-1007, doi: 10.1056/NEJMoa043814.

26. Rosenzweig A. Circulating endothelial progenitors - cells as biomarkers. N Engl J Med 2005; 353: 1055-1057, doi: 10.1056/NEJMe058134. 
27. Asahara T, Murohara T, Sullivan A, Silver M, van der Zee R, $\mathrm{Li} \mathrm{T}$, et al. Isolation of putative progenitor endothelial cells for angiogenesis. Science 1997; 275: 964-967, doi: 10.1126/science.275.5302.964.

28. Fina L, Molgaard HV, Robertson D, Bradley NJ, Monaghan $\mathrm{P}$, Delia D, et al. Expression of the CD34 gene in vascular endothelial cells. Blood 1990; 75: 2417-2426.

29. Salven P, Mustjoki S, Alitalo R, Alitalo K, Rafii S. VEGFR-3 and CD133 identify a population of CD34 + lymphatic/ vascular endothelial precursor cells. Blood 2003; 101: 168172, doi: 10.1182/blood-2002-03-0755.

30. Reyes M, Dudek A, Jahagirdar B, Koodie L, Marker PH, Verfaillie CM. Origin of endothelial progenitors in human postnatal bone marrow. J Clin Invest 2002; 109: 337-346, doi: $10.1172 / \mathrm{JCI} 0214327$.
31. Silvestre JS, Gojova A, Brun V, Potteaux S, Esposito B Duriez $M$, et al. Transplantation of bone marrow-derived mononuclear cells in ischemic apolipoprotein E-knockout mice accelerates atherosclerosis without altering plaque composition. Circulation 2003; 108: 2839-2842, doi: 10.1161/01.CIR.0000106161.43954.DF

32. Aicher A, Heeschen C, Mildner-Rihm C, Urbich C, Ihling C Technau-Ihling $\mathrm{K}$, et al. Essential role of endothelial nitric oxide synthase for mobilization of stem and progenitor cells. Nat Med 2003; 9: 1370-1376, doi: 10.1038/nm948.

33. Kissel CK, Lehmann R, Assmus B, Aicher A, Honold J, Fischer-Rasokat $U$, et al. Selective functional exhaustion of hematopoietic progenitor cells in the bone marrow of patients with postinfarction heart failure. J Am Coll Cardiol 2007; 49: 2341-2349, doi: 10.1016/j.jacc.2007.01.095. 